\title{
The Role of Lymphatic Endothelial Cells in Liver Injury and Tumor Development
}

\author{
Veronika Lukacs-Kornek* \\ Department of Medicine II, Saarland University Medical Center, Homburg, Germany
}

Lymphatics and lymphatic endothelial cells (LECs) possess multiple immunological functions besides affecting immune cell migration, such as inhibiting $T$ cell proliferation and antigen presentation by dendritic cells. Moreover, they control the trans-endothelial transport of multiple molecules and antigens. Emerging evidence suggest their active involvements in immunregulation, tumor, and metastases formation. In the liver, increased lymphangiogenesis, specifically at the portal area has been associated with multiple liver diseases in particular primary biliary cirrhosis, idiopathic portal hypertension, and liver

OPEN ACCESS

Edited by:

Sonia Elhadad,

Weill Cornell Medical College, USA

Reviewed by:

Anne L. Fletcher,

University of Birmingham, UK

Ditte Lindemann Hedegaard

contributed to the review of

Anne L. Fletcher

Frank Tacke,

University Hospital Aachen, Germany

${ }^{*}$ Correspondence:

Veronika Lukacs-Kornek veronika.lukacs-kornek@uniklinikumsaarland.de,

lukacsver@aol.com

Specialty section:

This article was submitted to Inflammation,

a section of the journal

Frontiers in Immunology

Received: 03 October 2016 Accepted: 16 November 2016

Published: 29 November 2016

Citation:

Lukacs-Kornek V (2016) The Role of Lymphatic Endothelial Cells in Liver Injury and Tumor Development.

Front. Immunol. 7:548.

doi: 10.3389/fimmu.2016.00548 malignancies. Nevertheless, the exact role and contribution of LECs to liver diseases are poorly understood. The review summarizes the current understanding of LECs in liver diseases.

Keywords: lymphatic endothelial cells, lymphatics, liver injury, HCC

\section{LIVER AS A LYMPHOID ORGAN}

The liver primarily operates as a metabolic center to maintain homeostasis that includes processing of gut-derived nutrients, the clearance of toxins, and the production of the bile (1). Besides these well-known functions, it is also considered as a lymphoid organ (2). This is on one hand due to the fact that non-parenchymal cells, such as hepatic stellate cells (HSCs) and liver sinusoidal endothelial cells (LSECs), take on antigen presenting and immunomodulatory functions to create a tolerant microenvironment $(2,3)$. On the other hand, the liver encompasses large populations of resident immune cells, such as Kuppfer cells, NK, T, and NKT cells that shape the local immune response, respond to danger signals and closely interact with parenchymal and non-parenchymal liver cells (3). These resident immune cells are located within the sinusoids where the mixture of arterial and venous blood carrying oxygen and gut-derived metabolic products arrives into the liver. From the sinusoids blood flows toward the central vein and finally leaves the liver conveying blood to the vena cava inferior. It is less known about the lymphatic circulation of the liver despite of the fact that it produces between $25-50 \%$ of the total lymph received by the thoracic duct $(4,5)$. This review summarizes the current understanding of the lymphatics of the liver and their known functions under steady state and during liver injury. Liver injuries manifest in various diseases including autoimmune hepatitis, infectious [hepatitis $\mathrm{C}$ virus (HCV)- and hepatitis B virus (HBV)-induced liver hepatitis], and metabolic disorders. Major causes of metabolic injuries are alcoholic liver damage (manifesting

Abbreviations: CCL21, CC-chemokine ligand 21; $\mathrm{CCl}_{4}$, carbon tetrachloride; CCR7, C-C chemokine receptor type 7; CD, cluster of differentiation; cDC1/2, conventional dendritic cells type 1/2; FACS, fluorescence-activated cell sorting; FRCs, fibroblastic reticular cells; HSCs, hepatic stellate cells; LECs, lymphatic endothelial cells; LNs, lymph nodes; MS, mechanosensors; SLO, secondary lymphoid organs; SR, scavenger receptors; TLRs, toll-like receptors. 
in liver steatosis, hepatitis, and cirrhosis) and the diet-related non-alcoholic fatty liver disease (NAFLD). Biliary injuries involve primary sclerosing cholangitis and primary biliary cirrhosis that are considered as immune-mediated liver disorders. Independent of the diverse etiology, liver inflammation and damage trigger a wound healing process that progressively leads to liver fibrosis, cirrhosis, and end-stage liver disease (6).

\section{THE LYMPHATIC SYSTEM OF THE LIVER}

The hepatic lymphatic system is divided into a deep and a superficial fraction $(5,7)$. The former follows the hepatic vein and the portal tracts, and the later collects lymph from the convex and inferior surfaces of the liver. The lymph itself originates in the perisinusoidal space of Disse (4). At the hepatic sinusoids, the interstitial space contains collagen fibers that connect LSECs and hepatocytes and form the portal limiting plate. Thus, fluid from the sinusoids flows through this structure and moves toward the perilobular space (it is referred as the space of Mall) and finally enters the portal lymphatic vessels $(4,5,7,8)$. This fluid movement is attainable due to the hydrostatic pressure differences observed between the portal vein and the interstitial space (9). Additionally, because of pressure gradient between arterial capillaries and the interstitial space, some blood is filtered through the peribiliary capillaries that surround the interlobular bile ducts. Nevertheless, the contribution of this process for the total liver lymph output is less than $10 \%$ (10). Besides the above-described route, the interstitial fluid can also follow the interstitial space connected with the hepatic capsule that contains superficial lymphatic vessels $(5,7)$. Both, the deep and superficial lymphatics of the liver drain primarily to the hepatic/celiac lymph nodes (LNs) $(7,11)$.

\section{LYMPHATIC CONTENT AND CELLULAR TRANSPORT}

The lymph generated in the perisinusoidal space contains $80 \%$ of the proteins present in plasma (5). The content of the lymph gains increasing attention as it contains self-peptides derived from intracellular, membrane-associated, and matrix proteins $(12,13)$. Moreover, it carries apoptotic cellular materials, infectious agents and represents a remote communication system for small molecules (e.g., cytokines) and cell-derived vesicles between the organ and its draining LN (13-16). The relevance of small molecule/vesicle trafficking via the lymphatics to the etiology of liver diseases is entirely unexplored. Such self-antigen delivery can be a key in autoimmune liver diseases. Moreover, biliary content during bile obstruction leaks to the lymphatics at the portal tract $(5,17)$ and probably reaches the draining LNs. Since bile acids might trigger inflammatory responses and necroptosis, it could influence hepatic immune responses arising within the draining LN.

Due to the resident immune, parenchymal and nonparenchymal cells, a tolerogenic environment is created for immune responses within the liver (3). Nevertheless, if immunity is required as a response to for example pathogens either monocyte-derived DCs present in intrahepatic myeloid-cell aggregates for T cell population expansion (iMATEs) provide bases for efficient T cell responses (18) or cytotoxic T lymphocytes are generated by migratory DCs reaching the draining $\operatorname{LN}(19,20)$. On the other side of the immune spectrum, migratory DCs are likely involved in the generation of regulatory $\mathrm{T}$ cells toward dietary antigens in the liver-draining LN (21). The lymphatics thus represent a crucial channel for a potential immunogenic and tolerogenic response outside of the liver suppressive environment $(19,22)$. To ensure this function, the lymph transports various immune cells. Accordingly, electron microscopy studies revealed the presence of DCs in between the limiting plate of hepatocytes and in the interstitial space of portal tract (4). This migratory process is more active after LPS injection (4). Not only liver resident but also circulating DCs can enter the lymphatic system in the liver, and this DC blood-lymph translocation seems to alter DCs and creates a more tolerogenic phenotype under steady state $(23,24)$. This could be due to DC interaction en route with liver non-parenchymal cells such as LSECs (25) or with lymphatic endothelial cells (LECs) along the lymphatics (26). Thus, the lymphatic circulation of liver-resident DCs and the circulating DC translocation might contribute to important peripheral tolerogenic responses under steady state. The major migratory cell population is the $\mathrm{CDC} 1\left(\mathrm{CD} 11 \mathrm{c}^{+} \mathrm{CD} 103^{+} \mathrm{CD} 11 \mathrm{~b}^{-}\right)$cells, and it remains to be elucidated whether monocyte-derived DCs or cCD2 $\left(\mathrm{CD} 11 \mathrm{c}^{+} \mathrm{CD} 103^{-} \mathrm{CD} 11 \mathrm{~b}^{+}\right)$cells contribute to the migratory cell population under differing circumstances $(20,27)$.

DC migration is maintained by CCR7-CCL21 interaction, where CCL2 1 is secreted by LECs that are also positive for various adhesion molecules and glycoproteins that are involved in cellular transport, such as gp38, ICAM-1, and E-selectin $(28,29)$. Besides LECs, EM study revealed the presence of fibroblast-like cells close to collagen fibers at the portal area representing fibroblastic reticular cells (FRCs) (4). Migratory DCs display close correlation with FRCs near the portal tract (4). Accordingly, in human liver, a low number of gp $38^{+}$FRCs are present at the portal area under steady state (30). FRCs secrete CCL19 that guides DC migration and provide survival factors for immune cell homeostasis $(28,31)$. Importantly, under pathological conditions, such as in primary biliary cirrhosis, the portal FRC and LEC network extends and is associated with structures similar to tertiary lymphoid organs (30). Similarly, in murine $P$. acnes-induced granulomatous hepatitis, portal tract-associated lymphatic structures, so called PALTs, are formed where $\mathrm{T}$ and $\mathrm{B}$ cell responses arise (32). Further studies are necessary to clarify that such tertiary lymphoid structure formation is related to migratory and lymphatic changes in liver diseases or represent a pathological structure where $\mathrm{LN}$-independent immune responses influence disease progression.

Besides DCs, lymphocytes, plasma cells, and mast cells could be identified within the lymphatic vessels of the liver and near the portal tract under steady state $(4,5)$. While memory lymphocytes and plasma cells are common travelers within lymphatic vessels, the exact function of mast cells remains uncertain within the healthy liver. The later is especially intriguing, since mast cells release inflammatory mediators during various liver diseases and contribute as accessory cells to disease progression (33). The liver 
is especially rich in lymphocytes involving not only conventional $\mathrm{T}$ cells but also innate lymphoid cells that express lymphoid homing markers, such as CCR7 $(34,35)$. Nevertheless, future studies are necessary to determine to which extent the various lymphocyte subpopulations travel via the lymphatics from the liver and what are the biological consequences of their migration.

\section{LYMPHATIC ENDOTHELIAL CELLS OF THE LIVER}

Lymphatic endothelial cells are the building blocks of lymphatic capillaries and vessels and express variety of molecules that distinguish them from blood endothelial cells (BECs) such as CCL21 or cadherin-13 (Table 1) $(29,36)$. Most of these molecules refer to LECs within secondary lymphoid organs (SLO); however, some differences due to the liver environment could be observed (Table 1). For example, lymphatic vascular endothelial hyaluronan (Lyve-1) is specific for LECs in lymphoid organs but is present in LSECs and in some liver macrophages (37). The best way is to identify liver LECs based on their expression of CD31 and gp38 (podoplanin). Liver LECs are $\mathrm{CD} 45^{-} \mathrm{CD} 31^{+} \mathrm{gp} 38^{+}$and thus can be distinguished from FRCs $\left(\mathrm{CD} 45^{-} \mathrm{CD} 31^{-} \mathrm{gp} 38^{+}\right)$, from LSECs $\left(\mathrm{CD}^{-} 5^{-} \mathrm{CD} 31^{+} \mathrm{gp} 38^{-}\right)$, and from the recently described gp38+ liver progenitor cells (CD45 $\left.{ }^{-} \mathrm{CD} 31^{-} \mathrm{CD} 133^{ \pm} \mathrm{gp} 38^{+}\right)$(38).

Lymphatic endothelial cells not only provide the structural unit for the vessels but also are involved in additional biological processes. As discussed already, via its expression of cytokines and adhesion molecules, LECs guide immune cell migration. Additionally, they are active participants in the nearby arising immune responses. They directly diminish DC maturation and $\mathrm{T}$ cell proliferation and thus function as a negative regulatory circuit during immune responses $(26,29,39)$. A variety of immunoregulatory factors are expressed by LECs that enable these functions. For example, LECs secrete TGF $\beta$ and nitric oxide, all of which are immunosuppressive $(39,40)$. Additionally, LECs lack the expression of co-stimulatory molecules and instead are rich in co-inhibitory markers, such as PDL1 (29, 39, 41, 42).

Lymphatic endothelial cells also possess the ability to express self-antigens and induce CD8 $\mathrm{T}$ cell deletion and serve as antigen reservoir for CD4 $\mathrm{T}$ cell tolerance (41-43). They also

TABLE 1 | Summary of surface markers for identifying murine and human lymphatic endothelial cells.

\begin{tabular}{ll}
\hline $\begin{array}{l}\text { Endothelial markers } \\
\text { (LECs and BECs) }\end{array}$ & Endothelial markers excluded from BECs \\
\hline ICAM-1 (CD54) & ${\text { Lyve- } 1^{\mathrm{a}}}_{\text {CD44 }}$ \\
& Prox-1 \\
VEGFR3 \\
CD31 & CCL21 \\
CD34 & Desmoplakin \\
& Integrin $\alpha 9, \alpha 1$ \\
E-, P-selectin & B-chemokine receptor D6 \\
Plakophilin & Cadherin-13 \\
& MMR \\
& Gp38 (podoplanin)
\end{tabular}

aPresent in liver LSECs and some liver macrophages.

BECs, blood endothelial cells; MMR, macrophage mannose receptor. possess surface receptors for endocytotic activity and able to sample from their environment (44). Importantly, most of these immunomodulatory potentials are connected with LECs present in SLO, thus raising the question what are the similarities and differences between SLO-associated LECs and LECs present along the lymphatic vessels. Unfortunately, such comparison studies have not been conducted. It is also uncertain whether liver LECs are able to acquire soluble antigens from the lymph and have antigen-presenting capacity.

Lymphatic endothelial cells are also actively involved in cholesterol homeostasis, and the removal of cholesterol by lymphatic vessels is dependent on the uptake of HDL by scavenger receptor class B type I expressed in LECs (45-47). In line with this, endothelial O-glycan deficiency led to disorganized lymphatic vessels and resulted in the development of fatty liver disease (NAFLD) due to the missing lymphatic removal of gut-derived lipid products (48). Since lipid metabolic changes are associated with various liver diseases, it will be interesting to evaluate in more details how this affects lymphatic function and vice versa how lymphatic changes are reflected in liver metabolic alterations.

\section{LYMPHATICS AND LIVER DISEASES}

\section{Chronic Liver Diseases}

Multiple studies have demonstrated that the lymphatic system is significantly altered during liver diseases. The number of lymphatic vessels as well as the lymphatic flow increases in fibrotic and cirrhotic livers $(37,49-52)$. This is in line with observations that VEGF-C and VEGF-D expression is elevated during fibrosis $(51,53,54)$. More importantly, the increased lymphangiogenesis is positively correlated with disease severity $(49,52)$. Moreover, the higher flow observed within the lymphatics during liver diseases could have additional consequences. Increased interstitial flow elevates the expression of cell recruiting cytokines (e.g., CCL21) and thus influences immune cell migration toward the draining LN (29). The flow at the same time likely reduces the portal pressure via channeling the excess fluid in cirrhosis and in portal hypertension (55).

Increased number of LECs is present during idiopathic portal hypertension (56), HCV-associated cirrhosis (52), and primary biliary cirrhosis (50). Given the wide-range of biological processes where LECs are involved, it is likely that the increase in the number of lymphatic vessels possesses functions exceeding fluid handling. The inflammatory environment triggers cytokine production in LECs and therefore increases immune cell recruitment (29). Additionally, bacterial products such as LPS (that is increased in portal vein during cirrhosis) induce not only chemoattracting cytokine production but also can activate $\mathrm{Nf}-\mathrm{Kb}$ in LECs and thus consequently upregulate Prox1 and VEGFR-3 (57). Both molecules raise the sensitivity to VEGF-C and VEGF-D and thus influence lymphangiogenesis $(57,58)$. Within the liver, this remains to be elucidated.

\section{Liver Tumor and Metastases Development}

One of the consequences of liver diseases is the development of hepatocellular carcinoma (HCC). Human HCC samples 
A
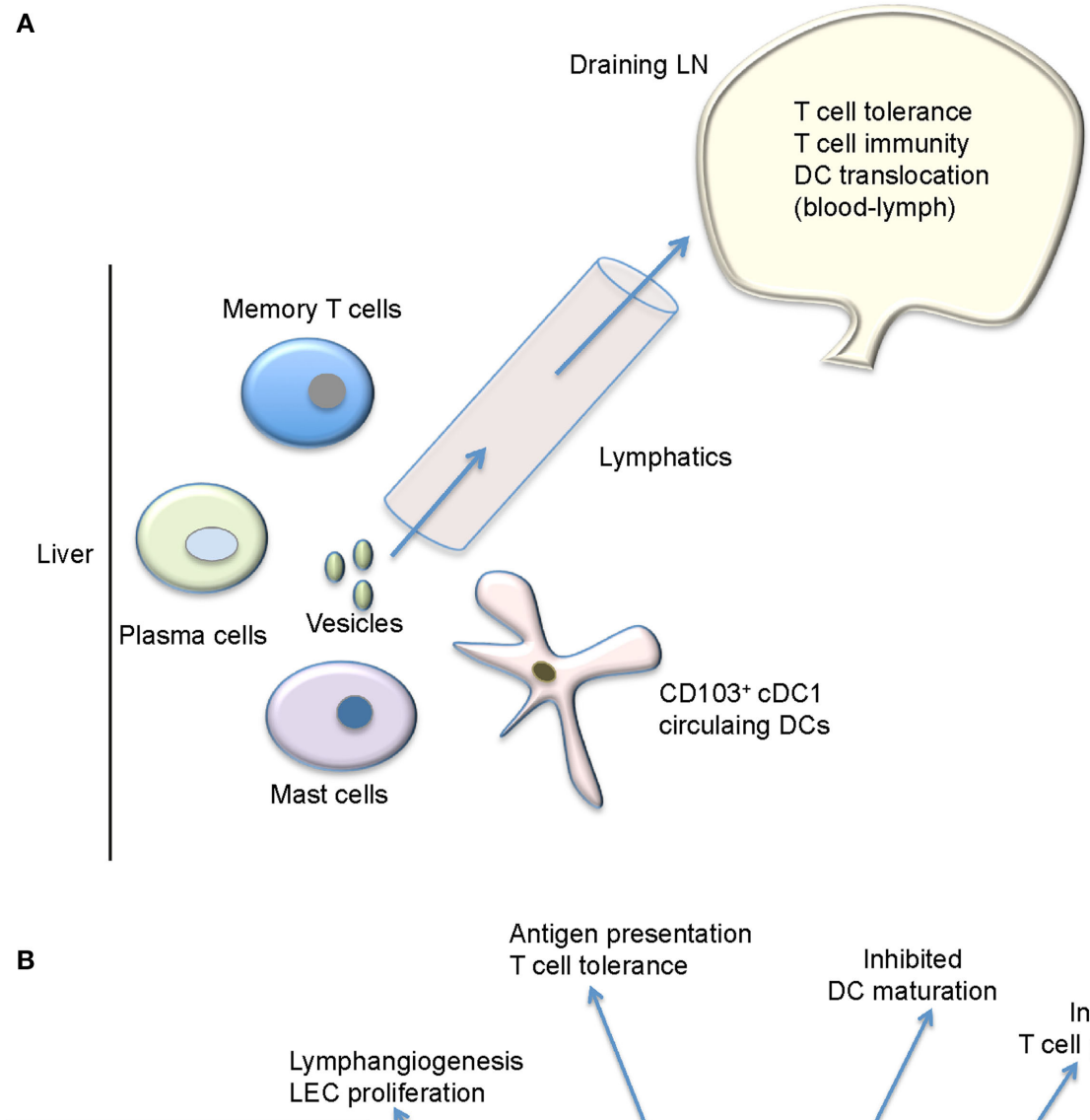

Antigen presentation

\section{$T$ cell tolerance Inhibited}

Increased LECs/lymphatics idiopathic portal hypertension $\mathrm{HCV}$

primary biliary cirrhosis
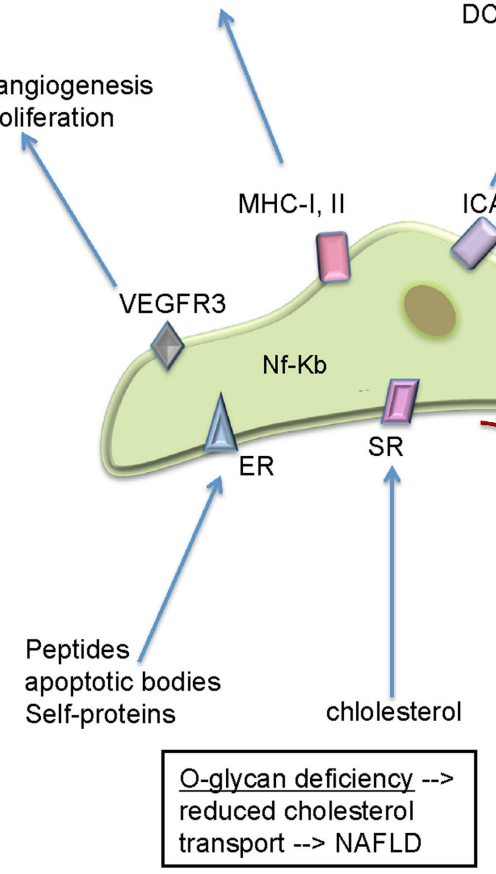

DC maturation

Inhibited
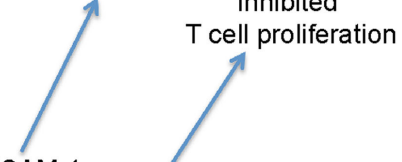

CAM-1
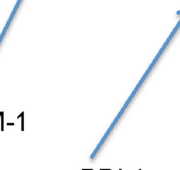

PDL1

Inflammatory cytokine production

TLRs
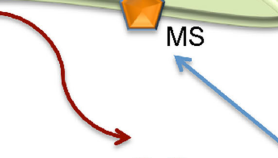

R

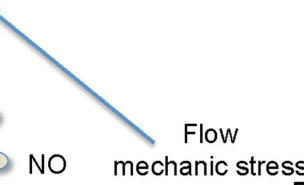

CCL21 TGF $\beta$

Increased CCL21 expression

Flow changes

granulomatous hepatitis

portal hypertension

$\mathrm{HCV}$

primary biliary cirrhosis

\begin{tabular}{|l|}
\hline Tumor metastases \\
\hline CCC \\
ICC \\
HCC \\
\hline
\end{tabular}

FIGURE 1 | The functional role of the lymphatics within the liver. (A) Besides fluid handling, the hepatic lymphatics transport various immune cell types, proteins, and vesicles to the draining LN. The LN provides the environment where not only tolerogenic but also immunogenic T cell response can arise that target liver pathogens/antigens. (B) LECs exhibit a variety of immunoregulatory functions that might be relevant for liver diseases. Future studies are necessary to evaluate all of these possibilities. Liver diseases with lymphatic/LEC alterations are depicted. CCC, colorectal carcinoma; ER, endocytic receptor; HCC, hepatocellular carcinoma; ICC, intrahepatic cholangiocytes carcinoma; MS, mechanosensors; SR, scavenger receptors, TLRs, toll-like receptors. 
displayed Lyve- $1^{+}$cells in the tumor-surrounding environment (37), and lymphatic vessels are present in the vicinity of metastatic liver tumors $(37,59,60)$. In line with this observation, VEGF-C- or VEGF-D-expressing liver tumors are more prone to spread within the liver (60). The liver metastases of colorectal cancer also exhibit gp $38^{+}$peri- and intra-tumoral lymphatic vessels that were correlated with tumor growth and metastases potential (61). Accordingly, intrahepatic invasion was the main prognostic marker for colorectal cancer and for intrahepatic cholangiocarcinoma and likely represents the main route of cancer dissemination in the liver (62-64). Indeed, intrahepatic cholangiocarcinoma is often associated with LN metastasis that translates to poorer outcome and reduced patient survival (63).

Lymphatic endothelial cells could facilitate such tumor cell spreading via CCL21-CCR7 interaction. Some colorectal cancer cells express CCR7 and thus could migrate toward the homeostatic chemokine CCL21 expressed by LECs (29). Additionally, lymphatic flow-induced chemokine gradient (e.g., CCl21 or CXCL12) could be sufficient to drive metastases of tumors positive for cytokines as observed in gliomas $(29,65)$. The exact mechanisms for HCC and other liver cancers are not well understood. Similarly, LECs display multiple immunomodulatory roles within the tumor microenvironment. LECs induce the recruitment of regulatory $\mathrm{T}$ cells, alter features of tumorassociated stroma, and contribute to the immunosuppressive milieu favoring tumor growth $(29,66,67)$. Additional studies are necessary to evaluate these possibilities also for liver cancers and metastases.

\section{REFERENCES}

1. Thomson AW, Knolle PA. Antigen-presenting cell function in the tolerogenic liver environment. Nat Rev Immunol (2010) 10:753-66. doi:10.1038/nri2858

2. Crispe IN. The liver as a lymphoid organ. Annu Rev Immunol (2009) 27:147-63. doi:10.1146/annurev.immunol.021908.132629

3. Eckert C, Klein N, Kornek M, Lukacs-Kornek V. The complex myeloid network of the liver with diverse functional capacity at steady state and in inflammation. Front Immunol (2015) 6:179. doi:10.3389/fimmu.2015.00179

4. Ohtani Y, Wang BJ, Poonkhum R, Ohtani O. Pathways for movement of fluid and cells from hepatic sinusoids to the portal lymphatic vessels and subcapsular region in rat livers. Arch Histol Cytol (2003) 66:239-52. doi:10.1679/ aohc.66.239

5. Ohtani O, Ohtani Y. Lymph circulation in the liver. Anat Rec (Hoboken) (2008) 291:643-52. doi:10.1002/ar.20681

6. Pellicoro A, Ramachandran P, Iredale JP, Fallowfield JA. Liver fibrosis and repair: immune regulation of wound healing in a solid organ. Nat Rev Immunol (2014) 14:181-94. doi:10.1038/nri3623

7. Yong TL, Houli N, Christophi C. Anatomy of hepatic lymphatics and its implications in hepatic malignancies. ANZ J Surg (2016) 86(11):868-73. doi:10.1111/ans.13662

8. Heath T, Lowden S. Pathways of interstitial fluid and lymph flow in the liver acinus of the sheep and mouse. J Anat (1998) 192(Pt 3):351-8. doi:10.1046/j.1469-7580.1998.19230351.x

9. Laine GA, Hall JT, Laine SH, Granger J. Transsinusoidal fluid dynamics in canine liver during venous hypertension. Circ Res (1979) 45:317-23. doi:10.1161/01.RES.45.3.317

10. Foldi M. [Lymph vessel system and liver: functional and pathophysiological relationship (author's transl)]. Leber Magen Darm (1974) 4:274-9.

11. Barbier L, Tay SS, McGuffog C, Triccas JA, McCaughan GW, Bowen DG, et al. Two lymph nodes draining the mouse liver are the preferential site of

\section{SUMMARY AND OUTLOOK}

Taken together, the liver is a unique metabolic and immunological niche within the body. Its lymphatic system represents a complex anatomical organization with a large lymph output. Based on the repertoire of the biological functions associated with lymphatics and LECs (Figure 1), it is suggested that LEC expansion is not only a passive accompanying event during liver diseases. This is particularly interesting since LEC changes seem to be reflective of the type of peripheral inflammation (68). Thus, this line of research urges more attention and studies that clarify its exact contribution to liver disease pathogenesis. This is possible, as improved marker combinations allow the flow cytometry detection and sorting of these cells from the liver. This, together with other techniques (e.g., histological analyses), provides solid basis for further functional investigations. This could raise our understanding of liver diseases and open novel therapeutic opportunities.

\section{AUTHOR CONTRIBUTIONS}

VL-K has designed and written the manuscript and prepared the table and the figure.

\section{FUNDING}

This work was supported by the Alexander von Humboldt Foundation, Sofja Kovalevskaja Award to VL-K.

DC migration and T cell activation. J Hepatol (2012) 57:352-8. doi:10.1016/ j.jhep.2012.03.023

12. Clement CC, Cannizzo ES, Nastke MD, Sahu R, Olszewski W, Miller NE, et al. An expanded self-antigen peptidome is carried by the human lymph as compared to the plasma. PLoS One (2010) 5:e9863. doi:10.1371/journal. pone.0009863

13. Clement CC, Rotzschke O, Santambrogio L. The lymph as a pool of self-antigens. Trends Immunol (2011) 32:6-11. doi:10.1016/j.it.2010. 10.004

14. Gretz JE, Norbury CC, Anderson AO, Proudfoot AE, Shaw S. Lymph-borne chemokines and other low molecular weight molecules reach high endothelial venules via specialized conduits while a functional barrier limits access to the lymphocyte microenvironments in lymph node cortex. J Exp Med (2000) 192:1425-40. doi:10.1084/jem.192.10.1425

15. Kunder CA, St John AL, Li G, Leong KW, Berwin B, Staats HF, et al. Mast cell-derived particles deliver peripheral signals to remote lymph nodes. J Exp Med (2009) 206:2455-67. doi:10.1084/jem.20090805

16. Gonzalez SF, Lukacs-Kornek V, Kuligowski MP, Pitcher LA, Degn SE, Kim YA, et al. Capture of influenza by medullary dendritic cells via SIGN-R1 is essential for humoral immunity in draining lymph nodes. Nat Immunol (2010) 11:427-34. doi:10.1038/ni.1856

17. Ewerth S, Bjorkhem I, Einarsson K, Ost L. Lymphatic transport of bile acids in man. J Lipid Res (1982) 23:1183-6.

18. Huang LR, Wohlleber D, Reisinger F, Jenne CN, Cheng RL, Abdullah Z, et al. Intrahepatic myeloid-cell aggregates enable local proliferation of CD8(+) $\mathrm{T}$ cells and successful immunotherapy against chronic viral liver infection. Nat Immunol (2013) 14:574-83. doi:10.1038/ni.2573

19. Bowen DG, Zen M, Holz L, Davis T, McCaughan GW, Bertolino P. The site of primary $\mathrm{T}$ cell activation is a determinant of the balance between intrahepatic tolerance and immunity. J Clin Invest (2004) 114:701-12. doi:10.1172/ JCI21593 
20. Krueger PD, Kim TS, Sung SS, Braciale TJ, Hahn YS. Liver-resident CD103+ dendritic cells prime antiviral CD8+ T cells in situ. JImmunol (2015) 194:3213-22. doi:10.4049/jimmunol.1402622

21. Hultkrantz S, Ostman S, Telemo E. Induction of antigen-specific regulatory $\mathrm{T}$ cells in the liver-draining celiac lymph node following oral antigen administration. Immunology (2005) 116:362-72. doi:10.1111/j.1365-2567.2005. 02236.x

22. Zheng M, Yu J, Tian Z. Characterization of the liver-draining lymph nodes in mice and their role in mounting regional immunity to HBV. Cell Mol Immunol (2013) 10:143-50. doi:10.1038/cmi.2012.59

23. Kudo S, Matsuno K, Ezaki T, Ogawa M. A novel migration pathway for rat dendritic cells from the blood: hepatic sinusoids-lymph translocation. J Exp Med (1997) 185:777-84. doi:10.1084/jem.185.4.777

24. Matsuno K, Kudo S, Ezaki T. The liver sinusoids as a specialized site for bloodlymph translocation of rat dendritic cells. Adv Exp Med Biol (1997) 417:77-81. doi:10.1007/978-1-4757-9966-8_13

25. Schildberg FA, Hegenbarth SI, Schumak B, Scholz K, Limmer A, Knolle PA. Liver sinusoidal endothelial cells veto CD8 $\mathrm{T}$ cell activation by antigenpresenting dendritic cells. Eur JImmunol (2008) 38:957-67. doi:10.1002/ eji.200738060

26. Podgrabinska S, Kamalu O, Mayer L, Shimaoka M, Snoeck H, Randolph GJ, et al. Inflamed lymphatic endothelium suppresses dendritic cell maturation and function via Mac-1/ICAM-1-dependent mechanism. J Immunol (2009) 183:1767-79. doi:10.4049/jimmunol.0802167

27. Lukacs-Kornek V, Schuppan D. Dendritic cells in liver injury and fibrosis: shortcomings and promises. JHepatol (2013) 59:1124-6. doi:10.1016/ j.jhep.2013.05.033

28. Lukacs-Kornek V, Turley SJ. Self-antigen presentation by dendritic cells and lymphoid stroma and its implications for autoimmunity. Curr Opin Immunol (2011) 23:138-45. doi:10.1016/j.coi.2010.11.012

29. Swartz MA. Immunomodulatory roles of lymphatic vessels in cancer progression. Cancer Immunol Res (2014) 2:701-7. doi:10.1158/2326-6066. CIR-14-0115

30. Link A, Hardie DL, Favre S, Britschgi MR, Adams DH, Sixt M, et al. Association of T-zone reticular networks and conduits with ectopic lymphoid tissues in mice and humans. Am J Pathol (2011) 178:1662-75. doi:10.1016/ j.ajpath.2010.12.039

31. Mueller SN, Germain RN. Stromal cell contributions to the homeostasis and functionality of the immune system. Nat Rev Immunol (2009) 9:618-29. doi: $10.1038 / \mathrm{nri} 2588$

32. Yoneyama $\mathrm{H}$, Matsuno $\mathrm{K}$, Zhang $\mathrm{Y}$, Murai M, Itakura M, Ishikawa S, et al. Regulation by chemokines of circulating dendritic cell precursors, and the formation of portal tract-associated lymphoid tissue, in a granulomatous liver disease. J Exp Med (2001) 193:35-49. doi:10.1084/jem.193.1.35

33. Francis $\mathrm{H}$, Meininger $\mathrm{CJ}$. A review of mast cells and liver disease: what have we learned? Dig Liver Dis (2010) 42:529-36. doi:10.1016/j.dld.2010.02.016

34. Mackley EC, Houston S, Marriott CL, Halford EE, Lucas B, Cerovic V, et al. CCR7-dependent trafficking of RORgamma(+) ILCs creates a unique microenvironment within mucosal draining lymph nodes. Nat Commun (2015) 6:5862. doi: $10.1038 /$ ncomms 6862

35. Fan X, Rudensky AY. Hallmarks of tissue-resident lymphocytes. Cell (2016) 164:1198-211. doi:10.1016/j.cell.2016.02.048

36. Podgrabinska S, Braun P, Velasco P, Kloos B, Pepper MS, Skobe M. Molecular characterization of lymphatic endothelial cells. Proc Natl Acad Sci U S A (2002) 99:16069-74. doi:10.1073/pnas.242401399

37. Mouta Carreira C, Nasser SM, Di Tomaso E, Padera TP, Boucher Y, Tomarev SI, et al. LYVE-1 is not restricted to the lymph vessels: expression in normal liver blood sinusoids and down-regulation in human liver cancer and cirrhosis. Cancer Res (2001) 61(22):8079-84.

38. Eckert C, Kim YO, Julich H, Heier EC, Klein N, Krause E, et al. Podoplanin discriminates distinct stromal cell populations and a novel progenitor subset in the liver. Am J Physiol Gastrointest Liver Physiol (2016) 310:G1-12. doi:10.1152/ajpgi.00344.2015

39. Lukacs-Kornek V, Malhotra D, Fletcher AL, Acton SE, Elpek KG, Tayalia P, et al. Regulated nitric oxide release by fibroblastic reticular cells and lymphatic endothelial cells controls the expansion of activated $\mathrm{T}$ cells within lymph nodes. Nat Immunol (2011) 12:1096-104. doi:10.1038/ni.2112
40. Irigoyen M, Anso E, Salvo E, Dotor De Las Herrerias J, Martinez-Irujo JJ, Rouzaut A. TGFbeta-induced protein mediates lymphatic endothelial cell adhesion to the extracellular matrix under low oxygen conditions. Cell Mol Life Sci (2008) 65:2244-55. doi:10.1007/s00018-008-8071-9

41. Cohen JN, Guidi CJ, Tewalt EF, Qiao H, Rouhani SJ, Ruddell A, et al. Lymph node-resident lymphatic endothelial cells mediate peripheral tolerance via Aire-independent direct antigen presentation. J Exp Med (2010) 207:681-8. doi:10.1084/jem.20092465

42. Fletcher AL, Lukacs-Kornek V, Reynoso ED, Pinner SE, Bellemare-Pelletier A, Curry MS, et al. Lymph node fibroblastic reticular cells directly present peripheral tissue antigen under steady-state and inflammatory conditions. J Exp Med (2010) 207:689-97. doi:10.1084/jem.20092642

43. Rouhani SJ, Eccles JD, Riccardi P, Peske JD, Tewalt EF, Cohen JN, et al. Roles of lymphatic endothelial cells expressing peripheral tissue antigens in CD4 T-cell tolerance induction. Nat Commun (2015) 6:6771. doi:10.1038/ ncomms7771

44. Lund AW, Duraes FV, Hirosue S, Raghavan VR, Nembrini C, Thomas SN, et al. VEGF-C promotes immune tolerance in B16 melanomas and cross-presentation of tumor antigen by lymph node lymphatics. Cell Rep (2012) 1:191-9. doi:10.1016/j.celrep.2012.01.005

45. Lim HY, Thiam CH, Yeo KP, Bisoendial R, Hii CS, McGrath KC, et al. Lymphatic vessels are essential for the removal of cholesterol from peripheral tissues by SR-BI-mediated transport of HDL. Cell Metab (2013) 17:671-84. doi:10.1016/j.cmet.2013.04.002

46. Martel C, Li W, Fulp B, Platt AM, Gautier EL, Westerterp M, et al. Lymphatic vasculature mediates macrophage reverse cholesterol transport in mice. J Clin Invest (2013) 123:1571-9. doi:10.1172/JCI63685

47. Martel C, Randolph GJ. Atherosclerosis and transit of HDL through the lymphatic vasculature. Curr Atheroscler Rep (2013) 15:354. doi:10.1007/ s11883-013-0354-4

48. Fu J, Gerhardt H, McDaniel JM, Xia B, Liu X, Ivanciu L, et al. Endothelial cell O-glycan deficiency causes blood/lymphatic misconnections and consequent fatty liver disease in mice. JClin Invest (2008) 118:3725-37. doi:10.1172/ JCI36077

49. Vollmar B, Wolf B, Siegmund S, Katsen AD, Menger MD. Lymph vessel expansion and function in the development of hepatic fibrosis and cirrhosis. Am J Pathol (1997) 151:169-75.

50. Yamauchi Y, Michitaka K, Onji M. Morphometric analysis of lymphatic and blood vessels in human chronic viral liver diseases. Am J Pathol (1998) 153:1131-7. doi:10.1016/S0002-9440(10)65657-X

51. Tugues S, Morales-Ruiz M, Fernandez-Varo G, Ros J, Arteta D, Munoz-Luque $\mathrm{J}$, et al. Microarray analysis of endothelial differentially expressed genes in liver of cirrhotic rats. Gastroenterology (2005) 129:1686-95. doi:10.1053/ j.gastro.2005.09.006

52. Yokomori H, Oda M, Kaneko F, Kawachi S, Tanabe M, Yoshimura K, et al. Lymphatic marker podoplanin/D2-40 in human advanced cirrhotic liver re-evaluations of microlymphatic abnormalities. BMC Gastroenterol (2010) 10:131. doi:10.1186/1471-230X-10-131

53. Corpechot C, Barbu V, Wendum D, Kinnman N, Rey C, Poupon R, et al. Hypoxia-induced VEGF and collagen I expressions are associated with angiogenesis and fibrogenesis in experimental cirrhosis. Hepatology (2002) 35:1010-21. doi:10.1053/jhep.2002.32524

54. Kornek M, Raskopf E, Tolba R, Becker U, Klockner M, Sauerbruch T, et al. Accelerated orthotopichepatocellular carcinomas growth is linked to increased expression of pro-angiogenic and prometastatic factors in murine liver fibrosis. Liver Int (2008) 28:509-18. doi:10.1111/j.1478-3231.2008.01670.x

55. Witte MH, Dumont AE, Cole WR, Witte CL, Kintner K. Lymph circulation in hepatic cirrhosis: effect of portacaval shunt. Ann Intern Med (1969) 70:303-10. doi:10.7326/0003-4819-70-2-303

56. Oikawa H, Masuda T, Sato S, Yashima A, Suzuki K, Sato S, et al. Changes in lymph vessels and portal veins in the portal tract of patients with idiopathic portal hypertension: a morphometric study. Hepatology (1998) 27:1607-10. doi:10.1002/hep.510270621

57. Flister MJ, Wilber A, Hall KL, Iwata C, Miyazono K, Nisato RE, et al. Inflammation induces lymphangiogenesis through up-regulation of VEGFR-3 mediated by NF-kappaB and Prox1. Blood (2010) 115:418-29. doi:10.1182/ blood-2008-12-196840 
58. Saban MR, Memet S, Jackson DG, Ash J, Roig AA, Israel A, et al. Visualization of lymphatic vessels through NF-kappaB activity. Blood (2004) 104:3228-30. doi:10.1182/blood-2004-04-1428

59. Yamaguchi R, Yano H, Nakashima O, Akiba J, Nishida N, Kurogi M, et al. Expression of vascular endothelial growth factor-C in human hepatocellular carcinoma. J Gastroenterol Hepatol (2006) 21:152-60. doi:10.1111/j.1440-1746.2005.04217.x

60. Thelen A, Scholz A, Benckert C, Von Marschall Z, Schroder M, Wiedenmann B, et al. VEGF-D promotes tumor growth and lymphatic spread in a mouse model of hepatocellular carcinoma. Int J Cancer (2008) 122:2471-81. doi:10.1002/ ijc. 23439

61. Hadj AK, Malcontenti-Wilson C, Nikfarjam M, Christophi C. Lymphatic patterns of colorectal liver metastases. J Surg Res (2012) 173:292-8. doi:10.1016/ j.jss.2010.09.012

62. Korita PV, Wakai T, Shirai Y, Sakata J, Takizawa K, Cruz PV, et al. Intrahepatic lymphatic invasion independently predicts poor survival and recurrences after hepatectomy in patients with colorectal carcinoma liver metastases. Ann Surg Oncol (2007) 14:3472-80. doi:10.1245/s10434-0079594-2

63. Shirabe K, Mano Y, Taketomi A, Soejima Y, Uchiyama H, Aishima S, et al. Clinicopathological prognostic factors after hepatectomy for patients with mass-forming type intrahepatic cholangiocarcinoma: relevance of the lymphatic invasion index. Ann Surg Oncol (2010) 17:1816-22. doi:10.1245/ s10434-010-0929-z

64. Lupinacci RM, Mello ES, Pinheiro RS, Marques G, Coelho FF, Kruger JA, et al. Intrahepatic lymphatic invasion but not vascular invasion is a major prognostic factor after resection of colorectal cancer liver metastases. World J Surg (2014) 38:2089-96. doi:10.1007/s00268-014-2511-5

65. Swartz MA, Lund AW. Lymphatic and interstitial flow in the tumour microenvironment: linking mechanobiology with immunity. Nat Rev Cancer (2012) 12:210-9. doi:10.1038/nrc3186

66. Shields JD, Kourtis IC, Tomei AA, Roberts JM, Swartz MA. Induction of lymphoidlike stroma and immune escape by tumors that express the chemokine CCL21. Science (2010) 328:749-52. doi:10.1126/science.1185837

67. Lund AW, Wagner M, Fankhauser M, Steinskog ES, Broggi MA, Spranger S et al. Lymphatic vessels regulate immune microenvironments in human and murine melanoma. J Clin Invest (2016) 126:3389-402. doi:10.1172/JCI79434

68. Vigl B, Aebischer D, Nitschke M, Iolyeva M, Rothlin T, Antsiferova O, et al. Tissue inflammation modulates gene expression of lymphatic endothelial cells and dendritic cell migration in a stimulus-dependent manner. Blood (2011) 118:205-15. doi:10.1182/blood-2010-12-326447

Conflict of Interest Statement: The author declares that the research was conducted in the absence of any commercial or financial relationships that could be construed as a potential conflict of interest.

Copyright (C) 2016 Lukacs-Kornek. This is an open-access article distributed under the terms of the Creative Commons Attribution License (CC BY). The use, distribution or reproduction in other forums is permitted, provided the original author(s) or licensor are credited and that the original publication in this journal is cited, in accordance with accepted academic practice. No use, distribution or reproduction is permitted which does not comply with these terms. 